\title{
Case report: Fentanyl-associated intraoperative anaphylaxis with pulmonary edema
}

\author{
[Étude de cas: Anaphylaxie peropératoire avec adème pulmonaire associé au fentanyl]
}

Kenneth C. Cummings III MD, ${ }^{*}$ Katherina Arnaut CRNA

Purpose: To describe an atypical presentation of intraoperative anaphylaxis due to fentanyl.

Clinical features: A 40-yr-old otherwise healthy woman was admitted for abdominal hysterectomy. She denied any drug allergies or past adverse anesthetic reactions. Physical examination, vital signs, and laboratory findings were all within normal limits. Twenty minutes after induction of general anesthesia with propofol, lidocaine, fentanyl, and rocuronium, she developed sudden onset of hypotension and bronchospasm. She was treated with fluids and epinephrine, but nonetheless required mechanical ventilation for $48 \mathrm{hr}$. Chest $x$-ray revealed pulmonary edema which resolved over two days. She recovered completely and was discharged home. Subsequent skin testing showed reactions to fentanyl and succinylcholine. Because the patient had not received succinylcholine, the cause of her anaphylaxis was attributed to fentanyl. The patient later returned for her hysterectomy and tolerated spinal anesthesia with bupivacaine and morphine.

Conclusion: Anaphylaxis is a fulminant, unexpected, IgE-mediated allergic reaction which can be triggered by multiple agents. Common causative agents include neuromuscular blocking drugs, latex, antibiotics, colloids, hypnotics, and opioids. Fentanyl, however, is an extremely unusual cause of anaphylaxis. Pulmonary edema, although uncommon in anaphylaxis, can be a prominent feature, as was the case with this patient.

CAN J ANESTH 2007 / 54: 4 / pp 301-306

Objectif: Décrire la présentation atypique d'anaphylaxie peropératoire due au fentanyl.

Éléments cliniques : Une femme de 40 ans en bonne santé a été admise pour une hystérectomie abdominale. Elle ne se connaissait pas d'allergie aux médicaments ou avoir eu de réactions adverses à l'anesthésie par le passé. L'examen physique, les signes vitaux et les tests de laboratoire ont tous présenté des résultats normaux.
Elle a soudainement développé de l'hypotension ainsi qu'un bronchospasme vingt minutes après l'induction de l'anesthésie générale avec propofol, lidocaïne, fentanyl et rocuronium. On lui a administré des liquides et de l'épinéphrine, mais elle a tout de même eu besoin de ventilation mécanique durant $48 \mathrm{~h}$. Une radiographie des poumons a révélé un œdème pulmonaire qui s'est résorbé en deux jours. Elle s'est complètement rétablie et a pu rentrer à la maison. Des tests cutanés ultérieurs ont montré des réactions au fentanyl et au suxaméthonium. Puisque la patiente n'avait pas reçu de suxaméthonium, le fentanyl a été tenu responsable de son anaphylaxie. La patiente est revenue plus tard pour son hystérectomie et a toléré la rachianesthésie avec de la bupivacaïne et de la morphine.

Conclusion : L'anaphylaxie est une réaction allergique fulminante, inattendue, médiée par les lgE, qui peut être provoquée par de nombreux agents. Les bloqueurs neuromusculaires, le latex, les antibiotiques, les colloïdes, les hypnotiques et les opiacés sont tous des agents connus pour leur potentiel anaphylactique. Cependant, il est très inhabituel que le fentanyl cause l'anaphylaxie. L'œdème pulmonaire, bien que peu répandu lors d'une réaction anaphylactique, peut devenir un trait proéminent, comme dans le cas décrit ici.

LTHOUGH rare, intraoperative anaphylaxis can lead to significant morbidity or mortality. Because of its protean manifestations, anaphylaxis is often a clinical diagnosis until later testing. Vascular collapse and bronchospasm are hallmarks of this condition, but neither is universally present. Other findings, such as flushing or urticaria, are easily overlooked in surgical patients. Rarer signs may also become prominent and obscure the diagnosis.

Numerous agents have been identified as triggers of intraoperative anaphylaxis, the most common

From the Departments of Regional Practice Anesthesiology, ${ }^{*} \dagger$ and Outcomes Research, ${ }^{*}$ The Cleveland Clinic, Cleveland, Ohio, USA. Address correspondence to: Dr. Kenneth C. Cummings III, Department of Anesthesiology, Hillcrest Hospital, 6780 Mayfield Road, Mayfield Heights, Ohio 44124, USA. Phone: 440-312-3022; Fax: 440-312-6963; E-mail: cummink2@ccf.org

Financial support: None

Accepted for publication January 16, 2007.

Revision accepted January18, 2007. 
being neuromuscular blocking drugs (NMBDs) and latex..$^{1,2}$ In contrast, opioids rarely cause anaphylaxis. This report describes an unusual case of intraoperative anaphylaxis during a routine gynecologic procedure which was ultimately ascribed to iv fentanyl. The patient provided oral informed consent for publication of this report.

\section{Case report}

A 40 -yr-old $\mathrm{G}_{1} \mathrm{P}_{1001}$ woman with a history of bleeding from uterine leiomyomas was admitted for abdominal hysterectomy. Her past medical history was otherwise unremarkable. Past surgical and anesthetic history included hysteroscopy under sedation (with propofol, midazolam, and fentanyl) and an epidural catheter for labour analgesia. She reported significant postoperative nausea after her hysteroscopy which was treated with ondansetron and metoclopramide. Medications included escitalopram for anxiety. She denied any drug allergies.

On physical exam, she was 5 feet, 3 inches (160 $\mathrm{cm}$ ) tall and weighed $73 \mathrm{~kg}$. Vital signs were all within normal limits. Her airway, cardiac, and pulmonary examinations were normal. Laboratory studies including a complete blood count, electrolytes, glucose, and serum creatinine were also all within normal limits.

At the surgeon's request, general anesthesia was planned. The patient was taken to the operating room and standard monitors were applied. After preoxygenation by facemask, anesthesia was induced with propofol $150 \mathrm{mg} i \mathrm{v}$, preservative-free lidocaine $80 \mathrm{mg} i v$, fentanyl $100 \mu \mathrm{g} i v$, and midazolam $2 \mathrm{mg}$ $i v$. After mask ventilation was confirmed, rocuronium $40 \mathrm{mg}$ was given intravenously. Laryngoscopy and tracheal intubation were uneventful. After confirmation of tube placement, the patient was mechanically ventilated with sevoflurane $2 \%$ in $50 \%$ oxygen, $50 \%$ nitrogen. A latex-containing Foley catheter was then inserted into the bladder. Due to her history of nausea, dexamethasone $4 \mathrm{mg}$, metoclopramide $10 \mathrm{mg}$, and ondansetron $4 \mathrm{mg}$ were administered intravenously. Antibiotics were not given.

Approximately $20 \mathrm{~min}$ after induction but before skin incision, the electrocardiogram (ECG) showed brief episodes of supraventricular tachycardia (5-10 beats per episode). The patient was otherwise stable. The anesthetic was deepened and a total of $50 \mathrm{mg}$ esmolol was given intravenously in incremental doses. Over the next few minutes, the heart rhythm became sinus tachycardia at 120 beats. $\mathrm{min}^{-1}$. The patient's blood pressure decreased precipitously from a baseline of $124 / 72 \mathrm{mmHg}$ to $60 / 30 \mathrm{mmHg}$. Intravenous fluids were opened to gravity and ephedrine $10 \mathrm{mg}$

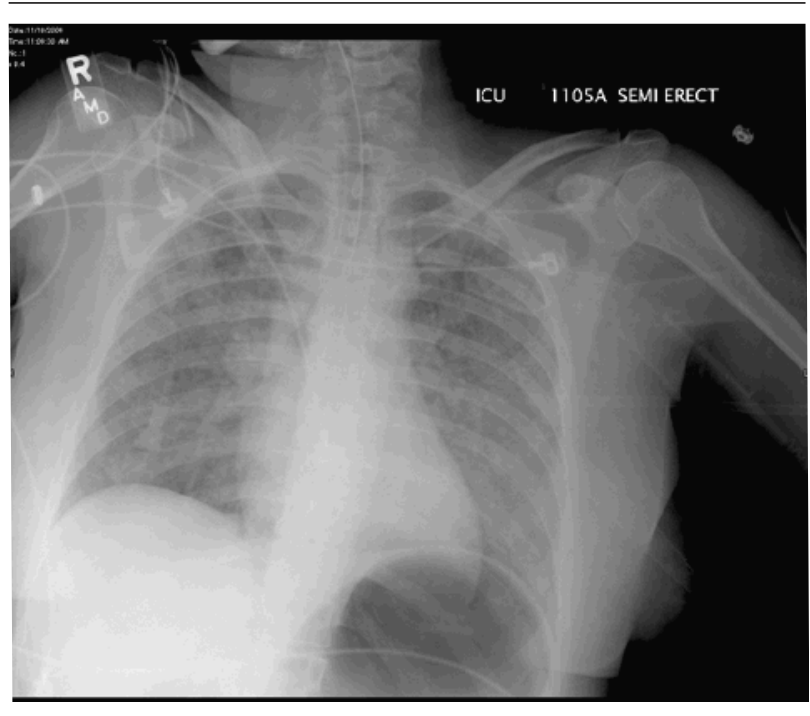

FIGURE Chest $x$-ray on intensive care unit admission.

iv was given without effect. Phenylephrine $200 \mu \mathrm{g}$ iv was then given which increased blood pressure only slightly to $70 / 50 \mathrm{mmHg}$. At this point, an ascending slope was noted on the capnogram, and the peak airway pressure was $30 \mathrm{~cm} \mathrm{H}_{2} \mathrm{O}$, up from a baseline of $20 \mathrm{~cm} \mathrm{H} \mathrm{H}_{2} \mathrm{O}$. Chest auscultation revealed bilateral wheezing, and the patient's oxyhemoglobin saturation $\left(\mathrm{SpO}_{2}\right)$ decreased from $100 \%$ to $90 \%$. The inspired oxygen concentration was increased to $100 \%$. An anaphylactic or anaphylactoid reaction was suspected, and epinephrine $20 \mu \mathrm{g}$ was given intravenously.

The patient's blood pressure improved with epinephrine $(130 / 80 \mathrm{mmHg})$, although peak airway pressures remained near $30 \mathrm{~cm} \mathrm{H}_{2} \mathrm{O}$. An examination of accessible skin revealed flushing of the neck and upper torso, but no other signs. Her blood pressure plummeted again, and copious frothy secretions were noted emerging from the endotracheal tube. Prominent rales were heard on chest auscultation. Positive end-expiratory pressure (PEEP) $7.5 \mathrm{~cm} \mathrm{H}_{2} \mathrm{O}$ was applied in an effort to maintain alveolar recruitment.

Additional epinephrine was given, a radial arterial catheter was inserted, and arrangements were made to transfer the patient to our intensive care unit (ICU). The latex-containing Foley catheter was replaced with a polyvinyl chloride substitute. Arterial blood gases on an $\mathrm{F}_{1} \mathrm{O}_{2}$ of 1.0 demonstrated metabolic acidosis and relative hypoxemia: $\mathrm{pH} 7.26, \mathrm{pCO}_{2} 42 \mathrm{mmHg}$, $\mathrm{PO}_{2} 83 \mathrm{mmHg}$, with bicarbonate of $18.2 \mathrm{mEq} \cdot \mathrm{L}^{-1}$ (normal 22-26). An epinephrine infusion was started, and titrated to maintain systolic blood pressure greater than $90 \mathrm{mmHg}$. Hydrocortisone $300 \mathrm{mg}$, diphen- 
TABLE Arterial blood gas values

\begin{tabular}{llllll}
\hline Time after event $(\mathrm{hr})$ & 0 & 2 & 6 & 24 & 48 \\
\hline $\mathrm{pH}$ & 7.26 & 7.30 & 7.25 & 7.48 & 7.43 \\
$\mathrm{pCO}_{2}(\mathrm{mmHg})$ & 42 & 28 & 30 & 25 & 30 \\
$\mathrm{pO}_{2}(\mathrm{mmHg})$ & 83 & 106 & 207 & 209 & 136 \\
$\mathrm{HCO}_{3}^{-}\left(\mathrm{mEq} \cdot \mathrm{L}^{-1}\right)$ & 18.2 & 12.7 & 12.9 & 18.3 & 19.3 \\
$\mathrm{~F}_{\mathrm{I}} \mathrm{O}_{2}$ & 1.0 & 1.0 & 0.8 & 0.5 & 0.5 \\
\hline
\end{tabular}

hydramine $50 \mathrm{mg}$, and famotidine $20 \mathrm{mg}$ were given intravenously.

The surgery was cancelled and the patient was transferred to the ICU. Intravenous fluids given up to this point consisted of approximately $3 \mathrm{~L}$ of lactated Ringer's solution. Chest $x$-ray showed bilateral infiltrates consistent with pulmonary edema (Figure). Ventilation was continued with PEEP increased to 10 $\mathrm{cm} \mathrm{H}_{2} \mathrm{O}$. The patient continued to require epinephrine for blood pressure support. In light of the significant pulmonary edema, a central venous catheter was inserted to follow filling pressures as a guide for fluid management. Central venous pressures were normal, ranging from 2 to $8 \mathrm{~cm} \mathrm{H}_{2} \mathrm{O}$.

A transthoracic echocardiogram revealed normal chamber size and cardiac function. An ECG showed sinus tachycardia without ST segment or $\mathrm{T}$ wave changes. Serial troponin I values were abnormal, with a peak value of $1.33 \mathrm{ng} \cdot \mathrm{mL}^{-1}$ at eight hours (normal $\left.<0.05 \mathrm{ng} \cdot \mathrm{mL}^{-1}\right)$. Serial arterial blood gases were also obtained (Table).

Blood and sputum cultures were obtained which yielded no growth. An allergist was consulted, who concurred with the diagnosis of anaphylactic or anaphylactoid reaction. A latex radioallergosorbent test was negative. A serum tryptase concentration was ordered but not obtained.

Over the next two days, the patient's oxygenation improved, and the $\mathrm{F}_{1} \mathrm{O}_{2}$ was reduced. She continued, however, to have a metabolic acidosis which slowly resolved. The peak lactic acid concentration was 7.2 $\mathrm{mmol} \cdot \mathrm{L}^{-1}$ (normal $<2 \mathrm{mmol} \cdot \mathrm{L}^{-1}$ ). The epinephrine infusion was tapered off after about $24 \mathrm{hr}$. After $48 \mathrm{hr}$ of mechanical ventilation, the patient was conscious, hemodynamically stable, and well oxygenated. Her trachea was extubated and the patient was continued on facemask oxygen. She remained in the hospital another $24 \mathrm{hr}$ and was discharged home without apparent sequelae.

One week after discharge, the patient saw the allergist for skin testing. Scratch and intradermal tests were negative for midazolam, generic propofol, diprivan (AstraZeneca, Wilmington, DE, USA), rocuronium, and cisatracurium. Positive reactions (wheal and flare) were noted with both fentanyl and succinylcholine. The allergist advised the patient to avoid fentanyl and all paralytic agents if possible. She was also seen by the consulting cardiologist and underwent an exercise stress echocardiogram which was normal.

She returned one month after the initial event for her hysterectomy. With midazolam $2 \mathrm{mg}$ iv premedication, a spinal anesthetic containing $1.6 \mathrm{~mL}$ $0.75 \%$ hyperbaric bupivacaine and $150 \mu \mathrm{g}$ preservative-free morphine sulfate was given at the $\mathrm{L}_{2-3}$ level. Cefazolin $1 \mathrm{~g}$ was given intravenously without incident. Antiemetic prophylaxis was given intravenously including dexamethasone $4 \mathrm{mg}$, metoclopramide 10 $\mathrm{mg}$, and ondansetron $4 \mathrm{mg}$. Light sedation with propofol $\left(50 \mu \mathrm{g} \cdot \mathrm{kg}^{-1} \cdot \mathrm{min}^{-1}\right)$ and ketamine $(5-10$ $\left.\mu \mathrm{g} \cdot \mathrm{kg}^{-1} \cdot \mathrm{min}^{-1}\right)$ was continued throughout the case. Latex surgical gloves were used. Following surgery, the patient awakened readily and was transferred to the postanesthesia care unit without incident. She had an uneventful hospital course and was discharged home on postoperative day two.

\section{Discussion}

Anaphylaxis is a fulminant, unexpected IgE-mediated allergic reaction which can be triggered by multiple agents. A clinically indistinguishable syndrome, anaphylactoid reaction, can only be differentiated with later testing and is treated identically. Estimates from prior studies of the incidence of intraoperative anaphylaxis have ranged from one in 3,500 to one in 20,000 anesthetics. $^{3}$

Initial presentation can vary, potentially involving numerous organ systems. The most common system involved is cardiovascular (hypotension, arrhythmia, myocardial depression, cardiovascular collapse), followed by cutaneous (flushing, urticaria) and respiratory (bronchospasm, laryngeal edema) manifestations. ${ }^{2}$ The intraoperative period, however, poses numerous challenges to diagnosing anaphylaxis. Patients receive multiple drugs in close succession, are often unconscious and unable to relate symptoms, and are usually surgically draped, delaying recognition of cutaneous signs. This requires the anesthesiologist to be vigilant for what may initially be subtle indications.

The pathophysiology of anaphylaxis begins with binding of an allergen to $\operatorname{IgE}$ on the surface of mast cells and basophils with crosslinking of receptors and subsequent cell activation. The resultant massive release of mediators such as histamine, leukotrienes, kinins, and eosinophil chemotactic factor leads to 
bronchoconstriction, vasodilation, and increased capillary permeability. This process can continue, with progressive inflammation leading to a delayed "second wave" of symptoms six to eight hours later. ${ }^{4}$

Numerous drugs and substances have been implicated in triggering anaphylaxis. A recent survey ${ }^{1}$ found that NMBDs, most commonly rocuronium and succinylcholine, accounted for $58.2 \%$ of perioperative events. These were followed by latex (16.7\%), antibiotics $(15.1 \%)$, colloids $(4.0 \%)$, hypnotics $(3.4 \%)$, and opioids $(1.3 \%)$. Outside of the perioperative period, insect stings and certain foods (peanuts, shellfish, and tree nuts) are also common triggers.

As the most frequent intraoperative trigger, NMBDs have received much attention. A feature common to all NMBDs is two linked quaternary ammonium groups. This arrangement can bind to two separate IgE molecules and initiate the immune cascade. Individuals may be sensitized without prior exposure to NMBDs because quaternary ammonium moieties are present in many products including over-the-counter drugs, food products, and cosmetics. ${ }^{3}$

Latex, the fluid derived from the Hevea brasiliensis tree, is used in many rubber products such as surgical gloves, face masks, drug vial caps, and Foley catheters. This fluid contains several proteins which are believed to be the immunologic triggers of anaphylactic reactions. Increasing awareness of bloodborne pathogens and use of barrier precautions have exposed more individuals to this agent. Consequently, it is now a major trigger of anaphylaxis.

Opioid-induced anaphylaxis, however, is rare. Morphine contains a tertiary amine group which causes non-immune release of histamine. True allergic reactions to morphine are much rarer. Fentanyl, a phenylpiperidine derivative, is chemically dissimilar to morphine and, as such, does not cross-react with morphine derivatives. ${ }^{3}$ Because of this fact, the allergist chose not to test our patient for morphine allergy. To date, there have been three reported cases of fentanyl-induced anaphylaxis, ${ }^{5-7}$ one of which was subsequently retracted due to an undiagnosed latex allergy. ${ }^{8}$ In each of these cases, the reaction presented as hypotension and urticaria.

Treatment of perioperative anaphylaxis begins with removing the likely trigger and aborting the procedure if possible. One hundred percent oxygen should be applied. Intravenous fluids should be given to compensate for vasodilation. Epinephrine should be administered intravenously, both for its $\beta_{2}$ effects (bronchodilation) and its $\alpha_{1}$ effects (increased vascular resistance). Additionally, the $\beta$-agonist effect of epinephrine can inhibit further mediator release from mast cells and basophils. An epinephrine infusion may be necessary to support blood pressure. $\mathrm{H}_{1}$ and $\mathrm{H}_{2}$ antagonists and corticosteroids are useful to blunt later recurrence of the reaction. Invasive monitoring such as arterial blood pressure and central venous pressure measurements can help with hemodynamic management. In unclear cases, echocardiography or pulmonary artery catheterization may be of benefit. Regardless of the monitors used, admission to an ICU is warranted due to the possibility of airway edema or recurrent symptoms.

The causative agent cannot always be identified. A retrospective survey comparing suspected causes with the result of subsequent testing found that, in 49 of 67 cases, the suspected agent did not match testing results. ${ }^{9}$ Tryptase, a protease released from activated mast cells, can be used as a marker of immune activation. An elevated serum tryptase concentration in blood drawn within several hours after the event can be helpful, although it cannot differentiate between anaphylaxis and an anaphylactoid reaction. A normal result, however, does not exclude these diagnoses. ${ }^{10}$ Subsequent outpatient skin testing may also be useful, but suffers from variations in methodology and both false positive and false negative results. ${ }^{11,12}$ If utilized, skin testing should include both prick and intradermal tests, as each has its weaknesses: prick tests suffer from concentration dependence of the antigen and a lack of standardization, while intradermal tests are more prone to false positive results. ${ }^{13} \mathrm{~A}$ positive skin test (wheal-and-flare) to a suspected agent suggests the presence of relevant $\mathrm{IgE}$ antibodies.

Several features of this case merit discussion. First, pulmonary edema is rarely associated with anaphylaxis, but is not without precedent. ${ }^{14,15}$ Its rapid presentation in a relatively young woman with no cardiac disease, a normal echocardiogram, and normal central venous pressures suggests a noncardiac etiology. Since the patient was tracheally intubated and paralyzed, negative-pressure pulmonary edema from airway obstruction seems improbable. Without any increased risk for aspiration or a witnessed event, aspiration pneumonitis also seems unlikely. It is thus reasonable to suspect that anaphylaxis itself was the cause of pulmonary edema, especially as increased capillary permeability is a hallmark of the disorder.

The metabolic acidosis which developed in our patient was pronounced. Elevated lactic acid levels usually imply tissue ischemia. In the setting of profound vasodilation requiring epinephrine infusion, acidosis was likely due to a distributive shock pathophysiology. As the inflammatory process (and need for vasopressors) diminished, the acidosis slowly resolved. 
The elevation in troponin concentrations was concerning. The patient had no history of coronary artery disease and had good functional capacity. A lack of wall motion abnormalities on the postoperative echocardiogram and a subsequent negative stress test suggests that transient ischemia caused subendocardial myocardial injury. Severe vasodilation with insufficient coronary blood flow in the setting of aggressive epinephrine use may have created a significant energy supply-demand imbalance in the myocardium.

Subsequent skin testing (performed according to the recommendations of Mertes et al. ${ }^{12}$ ) revealed positive reactions to both fentanyl and succinylcholine. Given that the patient did not receive succinylcholine, fentanyl seems the likely cause. If all skin test results were negative, the diagnosis of anaphylactoid reaction would be more appropriate. The positive results, however, argue for the presence of causative antibodies. The patient was not tested for the antiemetic drugs she received, but her uneventful re-exposure to these same drugs argues against their triggering her anaphylaxis. One could argue that, since there is extensive cross-reactivity among NMBDs, ${ }^{16}$ antibodies to succinylcholine could have cross-reacted with rocuronium. In practice, however, false negative results are unlikely with the culprit drug because most errors with skin testing of NMBDs are false positives. ${ }^{13}$ The reaction to succinylcholine may also have been spurious, as there is a $9.3 \%$ prevalence of positive skin test results to NMBDs in the general population, without clinically-apparent allergic reactions. ${ }^{17}$

Although the skin test results suggest she could safely receive rocuronium or cisatracurium, the allergist instructed the patient to avoid NMBDs in the future if possible. Consequently, neuraxial anesthesia was chosen for her hysterectomy. This arguably overconservative advice may prove problematic for the patient and her anesthesiologists in future surgeries. We informed the patient that, given all the available results, she could receive NMBDs in the future if circumstances warranted.

In summary, this case describes an otherwise healthy woman who experienced intraoperative anaphylaxis most likely due to fentanyl allergy. Unlike the only other two reported cases of anaphylaxis to fentanyl, ours was complicated by pulmonary edema, lactic acidosis, and a prolonged requirement for mechanical ventilation. Clinicians should remain cognizant of the risk of intraoperative anaphylaxis as well as its treatment.

\section{Acknowledgement}

The authors sincerely thank Daniel Sessler, M.D. for his valuable advice and assistance with the preparation of this manuscript.

\section{References}

1 Mertes PM, Laxenaire MC, Alla F; Groupe d'Études des Réactions Anaphylactoïdes Peranesthésiques.

Anaphylactic and anaphylactoid reactions occurring during anesthesia in France in 1999-2000. Anesthesiology 2003; 99: 536-45.

2 Laxenaire MC, Mertes PM; Groupe d'Études des Réactions Anaphylactoïdes Peranesthésiques. Anaphylaxis during anaesthesia. Results of a two-year survey in France. Br J Anaesth 2001; 87: 549-58.

3 Hepner DL, Castells MC. Anaphylaxis during the perioperative period. Anesth Analg 2003; 97: 1381-95.

4 Roizen MF, Fleisher LA. Anesthetic implications of concurrent diseases. In: Miller RD (Ed.). Anesthesia, 6th ed. Philadelphia: Elsevier; 2005: 1092-3.

5 Bennett MJ, Anderson LK, McMillan JC, Ebertz JM, Hanifin JM, Hirshman CA. Anaphylactic reaction during anaesthesia associated with positive intradermal skin test to fentanyl. Can Anaesth Soc J 1986; 33: 75-8.

6 Fukuda T, Dobi S. Anaphylactic reaction to fentanyl or preservative. Can Anaesth Soc J 1986; 33: 826-7.

7 Zucker-Pinchoff B, Ramanathan S. Anaphylactic reaction to epidural fentanyl. Anesthesiology 1989; 71: 599-601.

8 Zucker-Pinchoff B, Chandler MJ. Latex anaphylaxis masquerading as fentanyl anaphylaxis: retraction of a case report. Anesthesiology 1993; 79: 1152-3.

9 Kroigaard M, Garvey LH, Menne T, Husum B. Allergic reactions in anaesthesia: are suspected causes confirmed on subsequent testing? Br J Anaesth 2005; 95: 46871.

10 Fisher MM, Baldo BA. Mast cell tryptase in anaesthetic anaphylactoid reactions. Br J Anaesth 1998; 80: 26-9.

11 Nasser SM, Ewan PW. Opiate-sensitivity: clinical characteristics and the role of skin prick testing. Clin Exp Allergy 2001; 31: 1014-20.

12 Mertes PM, Laxenaire MC, Lienhard A, et al.; EAACI Interest Group on Drug Hypersensitivity. Reducing the risk of anaphylaxis during anesthesia: guidelines for clinical practice. J Investig Allergol Clin Immunol 2005; 15: 91-101.

13 Dhonneur G, Combes X, Chassard D, Merle JC. Skin sensitivity to rocuronium and vecuronium: a randomized controlled prick-testing study in healthy volunteers. Anesth Analg 2004; 98: 986-9.

14 Gallerani M, Manzoli N, Fellin R, Simonato M, Orzincolo C. Anaphylactic shock and acute pulmonary edema after a single oral dose of acetazolamide. Am J Emerg Med 2002; 20: 371-2.

15 Low I, Stables S. Anaphylactic deaths in Auckland, New Zealand: a review of coronial autopsies from 1985 to 2005. Pathology 2006; 38: 328-32.

16 Matthey P, Wang P, Finegan BA, Donnelly $M$. 
Rocuronium anaphylaxis and multiple neuromuscular blocking drug sensitivities. Can J Anesth 2000; 47 : 890-3.

17 Porri F, Lemiere C, Birnbaum J, et al. Prevalence of muscle relaxant sensitivity in a general population: implications for preoperative screening. Clin Exp Allergy 1999; 29: 72-5.

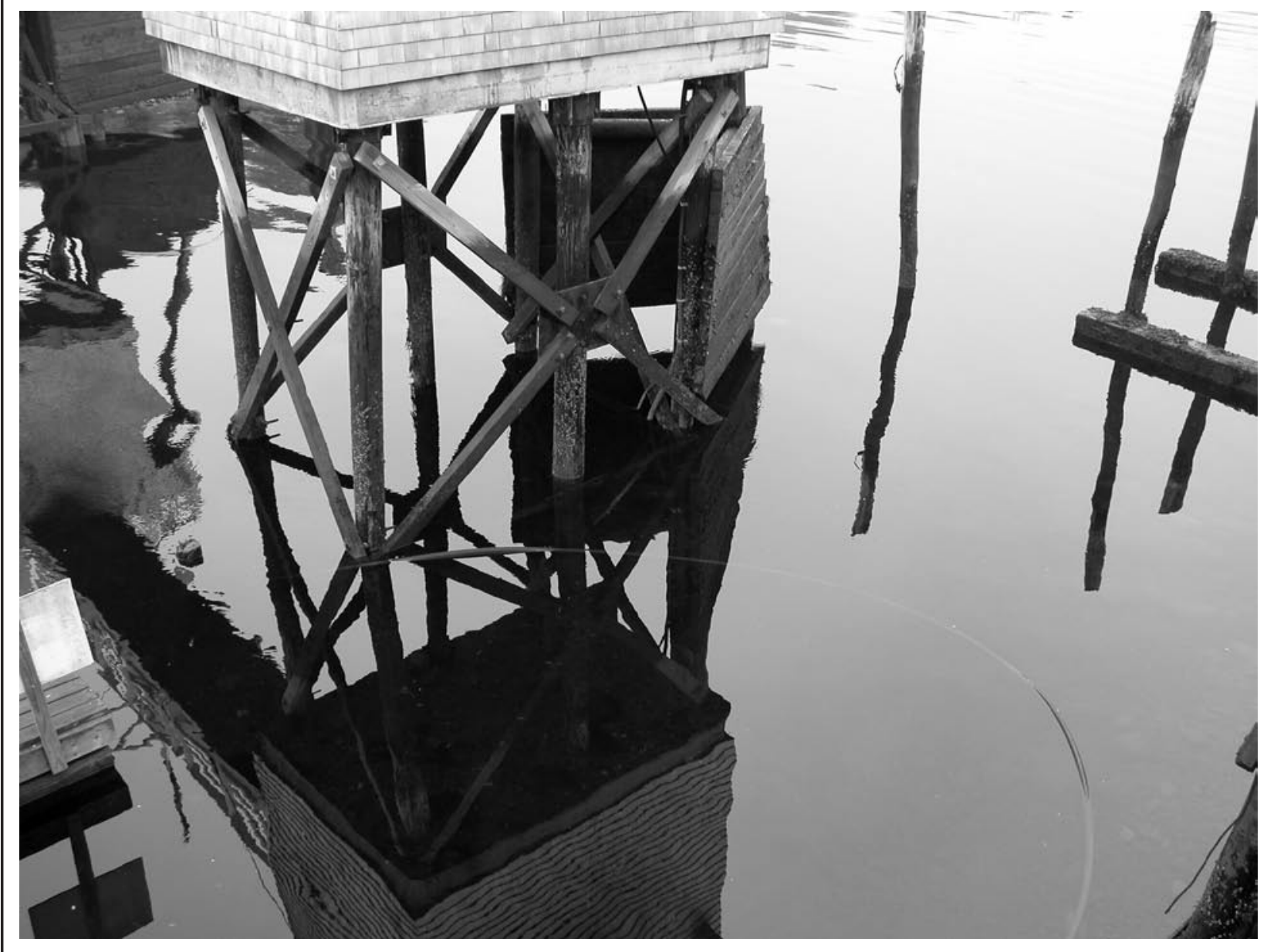

Ogunquit Maine - USA 